\title{
Dewatering model for optimal operation of sludge treatment wetlands
}

\author{
Enrica Uggetti, Albert Argilaga, Ivet Ferrer, Joan García* \\ GEMMA, Department of Hydraulic, Maritime and Environmental Engineering, Universitat Politècnica de Catalunya, \\ BarcelonaTech, c/Jordi Girona 1-3, Building D1, E-08034 Barcelona, Spain
}

\section{A R T I C L E I N F O}

Article history:

Received 15 July 2011

Received in revised form

1 October 2011

Accepted 18 October 2011

Available online 6 November 2011

\section{Keywords:}

Drying reed beds

Water loss

Water percolation

Evapotranspiration

Feeding frequency

\begin{abstract}
A B S T R A C T
Sludge treatment wetlands (STW) are used as a dewatering technology in some European countries since the 80's. Although the efficiency of this technology in terms of sludge dewatering and mineralisation is well known, design and operation parameters are yet to be standardised. The aim of this study is to develop a mathematical model capable of predicting the water loss with time, in order to optimise the feeding frequency enhancing sludge dewatering and expanding the lifespan of the system. The proposed model is validated with experimental data from one pilot and two full-scale STW. The scenarios considered indicate that the optimum feeding frequency decreases with the sludge layer height. In this way, systems with a sludge layer of $20 \mathrm{~cm}, 40 \mathrm{~cm}$ and $80 \mathrm{~cm}$ (corresponding to 2, 4 and 8 years of operation), should be fed every 2.5, 10 and 30-40 days, respectively. On the other hand, evapotranspiration (ET) has no effect on the feeding frequency, although it does increase the sludge dryness from $25 \%$ to $45 \%$ (for ET of 2.5 and $14.5 \mathrm{~mm}$ / $\mathrm{d}$ in the case of $20 \mathrm{~cm}$ of sludge height). According to the model output, the sludge loading rate is determined as a function of evapotranspiration, feeding frequency and sludge height.
\end{abstract}

(c) 2011 Elsevier Ltd. All rights reserved.

\section{Introduction}

Sludge treatment wetlands (STW), also known as drying reed beds, were developed at the end of the 80's. Sludge dewatering and mineralisation are the main features of this treatment. STW consist of sealed basins in which sewage sludge is spread onto the surface of a granular filter planted with wetland plants. The operation of these systems consists of feeding periods (from 1 to 10 days) followed by resting periods (from 4 days to 3 months). After feeding, part of the sludge water content is rapidly drained by gravity through the sludge residue and granular filter, while another part is evapotranspirated by the plants. A concentrated sludge layer remains on the surface of the bed. It increases by about
$10 \mathrm{~cm} /$ year when a surface sludge load around $60 \mathrm{~kg}$ TS/ $\mathrm{m}^{2}$.year is applied (Nielsen, 2003). When the sludge layer approaches the top of the basin, feeding is stopped during a final resting period (from $1-2$ months to 1 year) (Uggetti et al., 2010), aimed at improving the sludge dryness and mineralisation. The final product is subsequently withdrawn, starting the following operating cycle.

During the last decades, sludge dewatering and mineralisation have been investigated in pilot and full-scale STW differing on operation parameters (influent sludge, plant species, organic loading rate) and climate conditions (Bianchi et al., 2010; Lienard et al., 1994; Magri et al., 2010; Melidis et al., 2010; Stefanakis et al., 2009; Stefanakis and Tsihrintzis, 2011; Uggetti et al., 2009; Vincent et al., 2011). These studies have

\footnotetext{
* Corresponding author. Tel.: +34 934016464; fax: +34 934017357.

E-mail addresses: enrica.uggetti@upc.edu (E. Uggetti), ivet.ferrer@upc.edu (I. Ferrer), joan.garcia@upc.edu, joan.garcia@upc.es (J. García).

0043-1354/\$ - see front matter @ 2011 Elsevier Ltd. All rights reserved.

doi:10.1016/j.watres.2011.10.040
} 
shown that the feeding frequency is a key factor determining the sludge layer increase rate and, consequently, the duration of operating cycles. This is a matter of concern, since sludge withdrawal and transport are the main treatment costs (Uggetti et al., 2011). Indeed, optimisation of the resting period might reduce the system restoration cost by $25 \%$ (Giraldi and Iannelli, 2009).

Despite the importance of the feeding frequency, currently this operation parameter is not standardised. For instance, some Danish systems are fed for 7-8 days and rest for 55-56 days, while others are fed for 2-3 days and rest for 14-21 days (Nielsen, 2005, 2007). There are systems in France which are fed for 2 weeks and rest for 14 weeks (Troesch et al., 2008). Even if in some cases STW are only fed 3-8 times per year (Summerfelt et al., 1999; Obarska-Pempkowiak et al., 2003).

Assuming that the optimum feeding frequency corresponds to the period of maximum water loss, it could be optimised by modelling the water loss from the sludge layer with time. Such a dewatering model should integrate all elements contributing to the water balance of STW, namely: 1) water drainage, 2) evapotranspiration (ET) and 3) precipitation. Water drainage may be explained by the consolidation theory (Terzaghi and Peck, 1967). Consolidation is defined as the reduction of soil volume caused by the expulsion of water under long term static load. This process occurs when any stress (e.g. a load) is applied to a soil, causing water loss and bulk volume reduction. It refers to any process that involves a decrease in the water content of a saturated soil without replacement of water by air.

If we assume that the consolidation theory can be applied to sludge (Chu and Lee, 1999; Chang and Lee, 1998), water drainage in STW can be explained by the pressure exercised by the residual sludge layer. Evapotranspiration is the main component in the hydrology of wetlands (Zhou and Zhou, 2009). Indeed, efforts have been done to measure and simulate the ET of wetland plants in different regions of the world (Baird and Maddock, 2005; Borin et al., 2011; Zhongpong et al., 2010). Precipitation could be an important water source, depending on the climate conditions.

This work aims at developing a mathematical model to simulate sludge dewatering in STW, in order to optimase and standardise STW operation. The proposed model considers drainage (i.e. consolidation), ET and precipitation in a differential equation which is solved with a numerical method. Model validation is carried out with experimental data from one pilot and two full-scale STW. Different scenarios were then considered to get an insight on the optimum feeding frequency and sludge loading rate in different climate conditions. This model is a useful tool to optimise the feeding frequency, enhancing sludge dewatering and expanding STW operating cycles. To our knowledge this is the first time that a numerical model is developed and validated to improve STW operation.

\section{Material and methods}

\subsection{Model implementation}

\subsubsection{Drainage}

The main dewatering mechanism in STW immediately after loading is water percolation through the sludge residue. If the sludge layer compared well to an unsaturated soil, the process could be simulated by means of a porous flow model using the Richards equation. However, if we assume that the sludge layer is saturated for some days after loading, then the consolidation theory can be applied.

The process of consolidation is here explained in an ideal system composed of a spring, a container with a valve in its cover and water (Fig. 1). In this system, the spring represents the compressibility of the sludge and water represents pore water in the sludge. Initially, the container is full of water and the valve is closed, representing fully saturated sludge (Fig. 1a). If a certain load is applied to the cover when the valve is still closed, water pressure is developed (Fig. 1b). This corresponds to the pressure exercised by the weight of the sludge layer in STW. As soon as the valve is opened (Fig. 1c), water starts draining through the valve due to excess pore water pressure. This represents water percolation in STW. When excess pore water pressure is fully dissipated, water drainage stops and the spring alone resists the load (Fig. 1d).

The one-dimensional consolidation theory of Terzaghi (Terzaghi and Peck, 1967) is based on the following assumptions:

1. Soil is homogenous (uniform in composition throughout).

2. Soil is fully saturated (zero air voids due to the high water content).

3. Solid particles and water are incompressible (water density is constant and any change of soil volume is only due to change in void ratio).

4. Compression and flow are one-dimensional.

5. Strains in the soil are relatively small.

6. Flow of water in the soil voids is one-dimensional (Darcy's Law is valid for all hydraulic gradients).

7. The coefficient of permeability and the coefficient of volume compressibility remain constant throughout the process.

8. There is a unique relationship, independent of time, between the void ratio and effective stress.

Equation (1) is derived from Terzaghi's consolidation theory:

$c_{v} \frac{\partial^{2} u}{\partial z^{2}}=\frac{\partial u}{\partial t}$

where $C_{v}$ is the consolidation coefficient $\left(\mathrm{m}^{2} / \mathrm{s}\right), u$ is the interstitial pressure $\left(\mathrm{N} / \mathrm{m} \mathrm{s}^{2}\right), \mathrm{z}$ the distance (in our case, sludge height) $(\mathrm{m})$ and $t$ is time (s).

Equation (1) can be expressed as a dimensionless equation (Equation (2)) where $U$ is the consolidation ratio, $Z$ the point where consolidation is considered, $\mathrm{T}$ the time factor and $\Delta \sigma$ the pressure variation:

$\frac{\partial^{2} U}{\partial Z^{2}}=\frac{\partial U}{\partial T}$

where: $U=u / \Delta \sigma \quad Z=z / H \quad T=c_{v} t / H^{2}$

\subsubsection{Evapotranspiration and precipitation}

Evapotranspiration is calculated using the Penman-Monteith equation (Eq. (3)) (ASCE-EWRI, 2005).

$\mathrm{ET}_{0}=\frac{0.408 \cdot \Delta \cdot\left(R_{n}-G\right)+\gamma \frac{C_{n}}{\mathrm{~T}+273} u_{2} \cdot\left(e_{s}-e_{a}\right)}{\Delta+\gamma \cdot\left(1+C_{d} \cdot u_{2}\right)}$ 

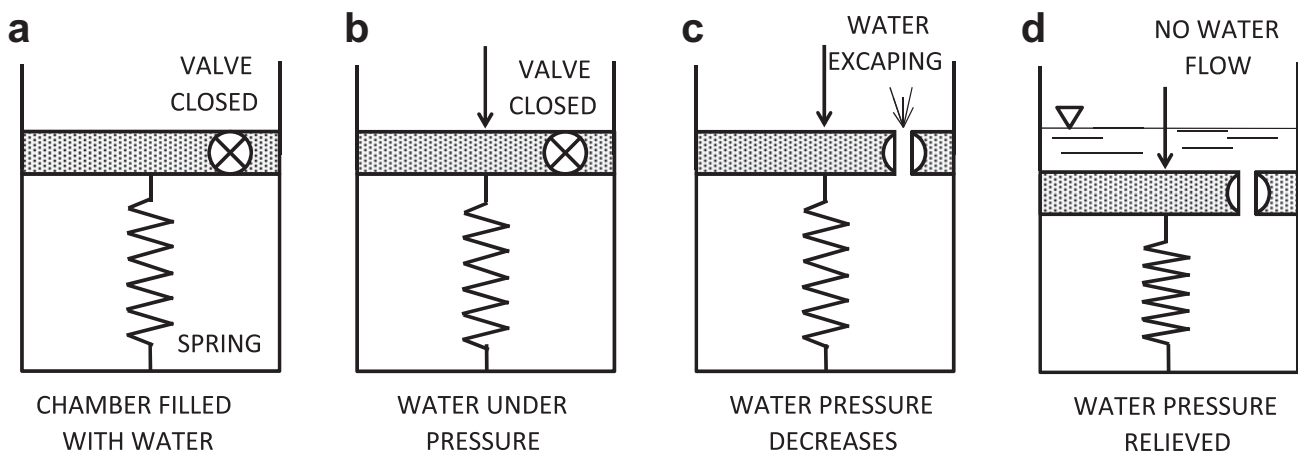

Fig. 1 - Diagram representing the process of consolidation. a) The container is completely filled with water and the hole (valve) is closed (fully saturated soil); b) a load is applied onto the cover, while the hole is still closed; c) the hole is opened and water drains out due to excess pressure; d) when excess pore water pressure is fully dissipated, flow through the soil pores ceases, and the system reaches an equilibrium position, with a compressed soil skeleton resisting the applied force (adapted from Lambe and Withman, 1979).

where $\mathrm{ET}_{0}$ is the standard reference for crop evapotranspiration $(\mathrm{mm} / \mathrm{d}), 0.408=1 / 2.45$ converts the unit from $\mathrm{MJ} / \mathrm{m}^{2} \mathrm{~d}$ to $\mathrm{mm} / \mathrm{d}, R_{n}$ is the calculated net radiation at the crop surface $\left(\mathrm{MJ} / \mathrm{m}^{2}\right), \mathrm{G}$ is the soil heat flow density at the soil surface (MJ/ $\mathrm{m}^{2} \mathrm{~d}$, approximated to zero), $\mathrm{T}$ is the mean daily air temperature at a height of $1.5-2.5 \mathrm{~m}\left({ }^{\circ} \mathrm{C}\right), u_{2}$ is the daily wind speed at a height of $2 \mathrm{~m}(\mathrm{~m} / \mathrm{s}), e_{\mathrm{s}}$ is the saturation vapour pressure at a height of $1.5-2.5 \mathrm{~m}(\mathrm{kPa})$ calculated for daily steps as the average of saturation vapour pressure at the maximum and minimum air temperature, $e_{a}$ is the mean vapour pressure at a height of $1.5-2.5 \mathrm{~m}(\mathrm{kPa}), \Delta$ is the slope of the saturation vapour pressure-temperature curve $\left(\mathrm{kPa} /{ }^{\circ} \mathrm{C}\right), \gamma$ is the psychometric constant $\left(\mathrm{kPa} /{ }^{\circ} \mathrm{C}\right) . \mathrm{C}_{n}$ and $\mathrm{C}_{d}$ are 900 and $0.34(\mathrm{~mm} / \mathrm{d})$ for short vegetation $(0.12 \mathrm{~m})$, and 1600 and $0.38(\mathrm{~mm} / \mathrm{d})$ for tall vegetation $(0.50 \mathrm{~m})$. Wetlands vegetation can be taller than $50 \mathrm{~cm}$, therefore the values for tall vegetation were taken as representative of the upper limit of ET (Allen et al., 2011).

If we convert ET and precipitation $(P)$ into pressure and introduce them in Eq. (2), we obtain Eq. (4):

$\frac{\partial^{2} U}{\partial Z^{2}}=\frac{\partial U}{\partial T}+Q \cdot \frac{\tau}{u_{0}}$

$Q=q \cdot \frac{U_{0}}{S_{\infty}}$

where $Q$ represents the pressure variation resulting from evapotranspiration and precipitation, contributing to water loss and water supply, respectively. In Eq. (5) the variable $q$ includes both ET and P. Consequently, negative values of $q$ indicate predominance of evapotranspiration, while positive ones indicate predominance of precipitation. $u_{0}$ is the initial pressure and $S_{\infty}$ represents the consolidation settlement after infinite time, when all overpressure has been dissipated $(U=1)($ Eq. (6)):

$S_{\infty}=\int_{0}^{H} \varepsilon(z, \infty) d z=\frac{a_{v}}{1+e_{0}} \cdot \Delta \sigma \cdot H$

where $a_{v}$ is the compressibility coefficient and $e_{0}$ the index of pore, which can be deduced by the porosity $n_{0}$ according to Eq. (7) $e_{0}=\frac{n_{0}}{1-n_{0}}$

The oedometric modulus $\left(E_{m}\right)$ is defined by Eq. (8):

$E_{m}=\frac{a_{v}}{1+e_{0}}$

$S_{\infty}$ becomes dimensionless by integrating the porosity $n_{\circ}$ (Eq. (9)):

$S_{\infty}=\frac{S_{\infty}}{n_{0} \cdot H}$

\subsubsection{Model solution}

The consolidation theory can be solved by means of analytical and tabulated solutions. In this case, however, the integration of ET and P makes the Terzaghi's model more complicated and a numerical method is required to solve Eq. (4). The software Matlab R2010 was here used to create a mesh representing the wetland section. The mesh had 120 nodes in the spatial direction and 240 time steps. This dimension was selected to set the relative error below $10^{-2}$ (moisture probe accuracy). The implicit method of finite difference was used to solve the differential equation at every time step. This method is stable for any time/space step relationship, meaning that the time step selected does not influence the solution.

ET and $P$ are applied uniformly in the space as source and sink terms, respectively. Indeed, plants roots are supposed to be uniformly distributed within the sludge layer, and so is precipitation.

Bearing in mind that pressure is caused by the sludge layer, initial and boundary conditions are set as follows: initial pressure is a function of the sludge layer height, while surface and bottom pressures are zero. This is due to the fact that both sides have free drainage: at the surface water can drain through the sludge layer, while at the bottom the gravel filter ease water percolation discharging the excess pore water pressure. Boundary conditions were selected in accordance with typical geotechnical problems. In this case, the pressure difference caused by the sludge layer is the main mechanism causing water loss. The final equilibrium state is reached after a long time, when at any value of the excess hydrostatic pressure is zero. 


\subsection{Model validation}

\subsubsection{Data collection}

Moisture data were collected by means of soil moisture probes SM 200 (Delta-T Devices Ltd) connected to a data logger GP 1 (Delta-T Devices Ltd). These probes consist of a sealed plastic body attached to two sensing rods which transmit an electromagnetic field into the sludge. The volumetric water content is determined from the permittivity, which a measures the medium response to polarisation in an electromagnetic field. In the case of sludge, its water content dominates the permittivity, which is measured by the moisture probe with an accuracy of $\pm 3 \%$. The probes measure the moisture of the medium in a volume of $0.5 \mathrm{dm}^{3}$ surrounding the two sensing rods. The calibration provided by the manufacturer for organic soils was verified for sludge. Therefore, sludge moisture was measured with probes located in situ at a depth of $10 \mathrm{~cm}$. Hourly measurements were recorded.

The volumetric water content given by moisture probes was converted to pressure in the same way as ET and P. According to Eq. (5), the volumetric values were multiplied by the overpressure and divided by the consolidation settlement after infinite time.

Meteorological data for ET calculation were gathered from the municipal meteorological stations of Barcelona Zona Universitaria and Perafita, Barcelona, Spain, located near the STW studied.

\subsubsection{Pilot and full-scale STW}

Data for model calibration were collected from a pilot plant located outdoors at the roof of the Department of Hydraulic, Maritime and Environmental Engineering of the Universitat Politècnica de Catalunya, Barcelona, Spain. This pilot plant was set up in winter 2008. It consists of three PVC containers with a surface area of $1 \mathrm{~m}^{2}$ and a height of $1 \mathrm{~m}$. Thickened activated sludge from a WWTP near Barcelona (extended aeration), was manually loaded since May 2008. The sludge loading rate was $0.025 \mathrm{~m}^{3} /$ week per STW, corresponding to $40 \mathrm{~kg} \mathrm{TS} / \mathrm{m}^{2}$.year. The STW used in this study had a granular filter composed by $10 \mathrm{~cm}$ of stones $\left(d_{50}=25 \mathrm{~mm}\right), 30 \mathrm{~cm}$ of gravel $\left(d_{50}=5 \mathrm{~mm}\right)$ and $10 \mathrm{~cm}$ of sand $\left(d_{50}=1 \mathrm{~mm}\right)$. Three perforated PVC pipes were located at the bottom of the filter to collect the leachate and ease filter aeration. The STW was planted with Phragmites australis.

Data for model verification was collected from two fullscale systems located in Alpens (400 PE) and Sant Boi de Lluçanès (1500 PE) in the province of Barcelona, Spain. The main characteristics of both facilities are summarised in Table 1; additional details may be found in Uggetti et al. (2009).

The pilot and full-scale STW were loaded once per week. In model validations the resting period ranged from 5 to 8 days, depending on moisture data availability.

\subsubsection{Model calibration and verification}

Two parameters were calibrated in order to solve Eq. (4): the consolidation coefficient $\left(C_{v}\right)$ and the oedometric coefficient $\left(E_{m}\right)$. Both parameters are related by Eq. (10). The consolidation coeficient defines the dissipation velocity of the pressure exercised by water in the sludge, which corresponds to the slope of the curve moisture vs. time. The oedometric
Table 1 - Main characteristic of the wastewater treatmen plants of Alpens and Sant Boi de Lluçanès, Barcelona, Spain.

\begin{tabular}{lcc} 
& Alpens & $\begin{array}{c}\text { Sant Boi de } \\
\text { Lluçanès }\end{array}$ \\
\hline $\begin{array}{l}\text { Population equivalent } \\
\text { Type of treatment } \\
\begin{array}{c}\text { Sludge production } \\
\text { (kg TS/d) }\end{array}\end{array}$ & $\begin{array}{c}400 \text { (800 design) } \\
\text { Extended aeration }\end{array}$ & $\begin{array}{c}600 \text { (1500 design) } \\
\text { Extended aeration }\end{array}$ \\
$\begin{array}{c}\text { Sludge flow rate } \\
\left(\mathrm{m}^{3} / \text { day) }\right.\end{array}$ & 30 & 45 \\
$\begin{array}{c}\text { Total surface area } \\
\text { of the STW }\left(\mathrm{m}^{2}\right)\end{array}$ & 2 & 3 \\
$\begin{array}{c}\text { Sludge loading rate } \\
\left(\mathrm{kg} \mathrm{TS} / \mathrm{m}^{2} \cdot \text { year }\right)\end{array}$ & 198 & 324 \\
\hline
\end{tabular}

coeficient is the sludge rigidity, which influences the final consolidation settlement.

$C_{v}=\frac{K \cdot E_{m}}{\gamma_{w}}$

where $K$ is the permeability $(\mathrm{m} / \mathrm{s})$ and $\gamma_{w}$ the water weight $\left(\mathrm{N} / \mathrm{m}^{3}\right)$.

$C_{v}$ (Eq. (1)) and $E_{m}$ (Eq. (8)) are usually determined by fitting a theoretical curve of consolidation with time deduced from the consolidation theory, with the curve obtained by laboratory tests. This method defines the compressibility curve and the consolidation coefficient of a soil sample subjected to a one-dimensional compression.

In our case, the standard consolidation test was not possible due to the nature of the sludge. Thus, model calibration was made by setting the sludge height $(H)$, index of void $\left(e_{0}\right)$, porosity $\left(n_{0}\right)$, evapotranspiration and precipitation (q). $\mathrm{H}$ was measured in situ and $\mathrm{n}_{0}$ deduced from moisture data obtained with probes located in situ. Thus, $C_{v}$ and $E_{m}$ values were determined by fitting the model simulation curve to moisture curves deduced from data collected in the pilot STW in May 2010. According to the data availability, the model was verified with data obtained mainly during the warm season (Alpens records from May and Sant Boi de Lluçanès records from February, May and June 2010). The calibration confidence interval corresponds to the probes accuracy $( \pm 3 \%)$.

The following statistical tests were used to test model performance: the Mean Absolute Error (MEA), the Mean Square Error Normalised (RMSEN), the Pearson's Correlation Coefficient (PCC), the Normalised Mean Bias Error (NMBE) and the Nash-Sutcliffe Coefficient of Efficiency (CE). The test are described in detail by Akratos et al. (2009). They were performed with Microsoft Excel 2010 and Minitab 15.0 Statistical Software. The significance of the difference between experimental data and the model output was assessed by means of the ANOVA test using the Minitab 15.0 statistical software.

\subsection{Scenarios}

\subsubsection{Feeding frequency}

Once the dewatering model was validated, different scenarios were considered to determine the optimum feeding frequency 
in different climate conditions of the Mediterranean Region. Three climate zones corresponding to mountain, coastal and dry continental climates were selected. In each zone, evapotranspiration was calculated for summer and winter seasons according to the Penman-Monteith equation (ASCE-EWRI, 2005). Meteorological data for ET calculation were gathered from municipal meteorological stations located in the zones considered. The lowest $(2.5 \mathrm{~mm} / \mathrm{d})$, average $(8.6 \mathrm{~mm} / \mathrm{d})$ and highest $(14.5 \mathrm{~mm} / \mathrm{d})$ ET values where considered as representative of the mountain, coastal and dry continental climates, respectively. These scenarios, characterised by different ET, can also be representative of different seasons. Indeed, average potential ET in summer oscillates between 3.6 and $5.2 \mathrm{~mm} / \mathrm{d}$ in the North and South of Italy, respectively (Borin et al., 2011). Precipitation was not considered in these simulations.

For each scenario, the following sludge layer heights were studied: 20, 40 and $80 \mathrm{~cm}$, according to the typical increase rate of $10 \mathrm{~cm} /$ year (Nielsen, 2003).

To determine the optimum feeding frequency based on ET and sludge layer height, the derivative of the dewatering curve was used. In order to enhance sludge dewatering, the optimum feeding frequency should include the whole period of sludge dewatering, and not only the maximum instant. This period corresponds to the maximum average dewatering. For this reason, the optimum feeding frequency was determined by calculating the cumulative moving average of the derivative distribution from $t=0$. The average of the derivative was calculated as a function of the time elapsed from sludge loading, with the Eq. (11):

average $=($ derivative $(1: T) / T)$

In this way, the peak of the cumulative moving average corresponds to the time interval of maximum water loss. Since the influence of ET on dewatering time is only minor, this calculation was made with $\mathrm{ET}=0$.

\subsubsection{Sludge loading rate}

The maximum water loss corresponding to each feeding frequency was calculated from the derivate of the dewatering curve. By means of the least squares regression, we found a logarithmic relationship between dewatering $(\Delta w)$ and sludge height $(H)$ for each feeding frequency $(T)$ and evapotranspiration (ET). Thus 15 equations like Eq. (12) were found,

$\Delta w(H)=a_{1} \cdot \ln (H)+b_{1}$

where $a_{1}$ and $b_{1}$ are numerical constants for each equation, and $w$ is the volume of water lost.

The numerical constants of the 15 equations obtained were correlated by means the least squares regression as a function of ET and 5 equations like Eq. (13) were derived, one for each feeding frequency $(T)$

$\Delta w(H, E T)=\left(a_{2} \cdot E T+b_{2}\right) \cdot \ln (H)+c_{2} \cdot E T+d_{2}$

where $a_{2}, b_{2} c_{2}$ and $d_{2}$ are numerical constants for each equation. By establishing the sludge loading rate (SLR) as the volume of water lost (w); SLR was determined by means of the least squares regression of Eq. (13).

\section{Results and discussion}

\subsection{Model validation}

The consolidation and oedometric coefficients obtained from model calibration were $C_{v}=3 \cdot 10^{-8} \mathrm{~m}^{2} / \mathrm{s}$ and $E_{\mathrm{m}}=4 \cdot 10^{4} \mathrm{~N} / \mathrm{m}^{2}$, respectively. These values are consistent with the literature, with $C_{v}$ ranging from $3 \cdot 10^{-10}$ to $3.5 \cdot 10^{-8} \mathrm{~m}^{2} / \mathrm{s}$ depending on permeability and compressibility (Lambe and Withman, 1979), and $E_{m}$ ranging from $5 \cdot 10^{5} \mathrm{~N} / \mathrm{m}^{2}$ in low consolidated sludge and $5 \cdot 10^{8} \mathrm{~N} / \mathrm{m}^{2}$ in sand. The lowest $E_{m}$ values from the model calibration are attributed to the sludge water content.

Fig. 2 shows the model verifications, carried out with data from the two full-scale STW in warm and cold seasons. In this Figure, the decrease of sludge moisture (or water loss) measured after loading is compared with the model output. In general all tests show a good response of the model (Table 2). The Mean Square Error Normalised (RMSEN) and the Normalised Mean Bias Error (NMBE) with values near zero support the validations. The Pearson's Correlation Coefficient (PCC), with values near 1 , indicates a positive correlation between measured and predicted results. According to the Absolute Error (MEA) and the Nash-Sutcliffe Coefficient of Efficiency (CE) the model fits better with data from Sant Boi de Lluçanès (validations 2 and 3) than Alpens (validation 4). According to the one-way ANOVA, experimental data and the model simulation are not significantly different $(p>0.01)$. Only in the case of Alpens (Fig. 2d) daily oscillations of experimental data caused problems in model adaptation, producing a significant difference between measured and simulated data $(p<0.01)$. Such daily variations in sludge moisture are attributed to the thin sludge layer $(15 \mathrm{~cm})$ which is strongly influenced by temperature and evapotranspiration effects. Although in some cases the curves simulated do not reproduce accurately the trend followed by experimental data (Fig. 2a and d), the final moisture values simulated by the model differ from experimental moisture values by less than $1 \%$. This means that the model is able to simulate water loss within the sludge layer, estimating rather well the sludge moisture at the end of the resting period (in this case 5-8 days). However, the model response to precipitations was not tested since no rainfalls occurred during the periods considered.

Notice that the model is valid for different seasons due to its strict dependence on evapotranspiration, which reflects climate conditions. In fact, the final moisture value predicted by the model corresponds to the value recorded by the probe both in winter (Fig. 2a), when sludge moisture is reduced by $5 \%$, and in spring (Fig. $2 b, c$ and $d$ ), when sludge moisture is reduced by $10 \%$ in 8 days. The comparison between the curves measured in February and May (Fig. 2a and b) highlights the difference between the water loss in different seasons. In winter (Fig. 2a) the initial sludge moisture is high (around 92\%) and the water loss is low due to a low evapotranspiration rate, which does not enhance sludge drying during the cold season. 

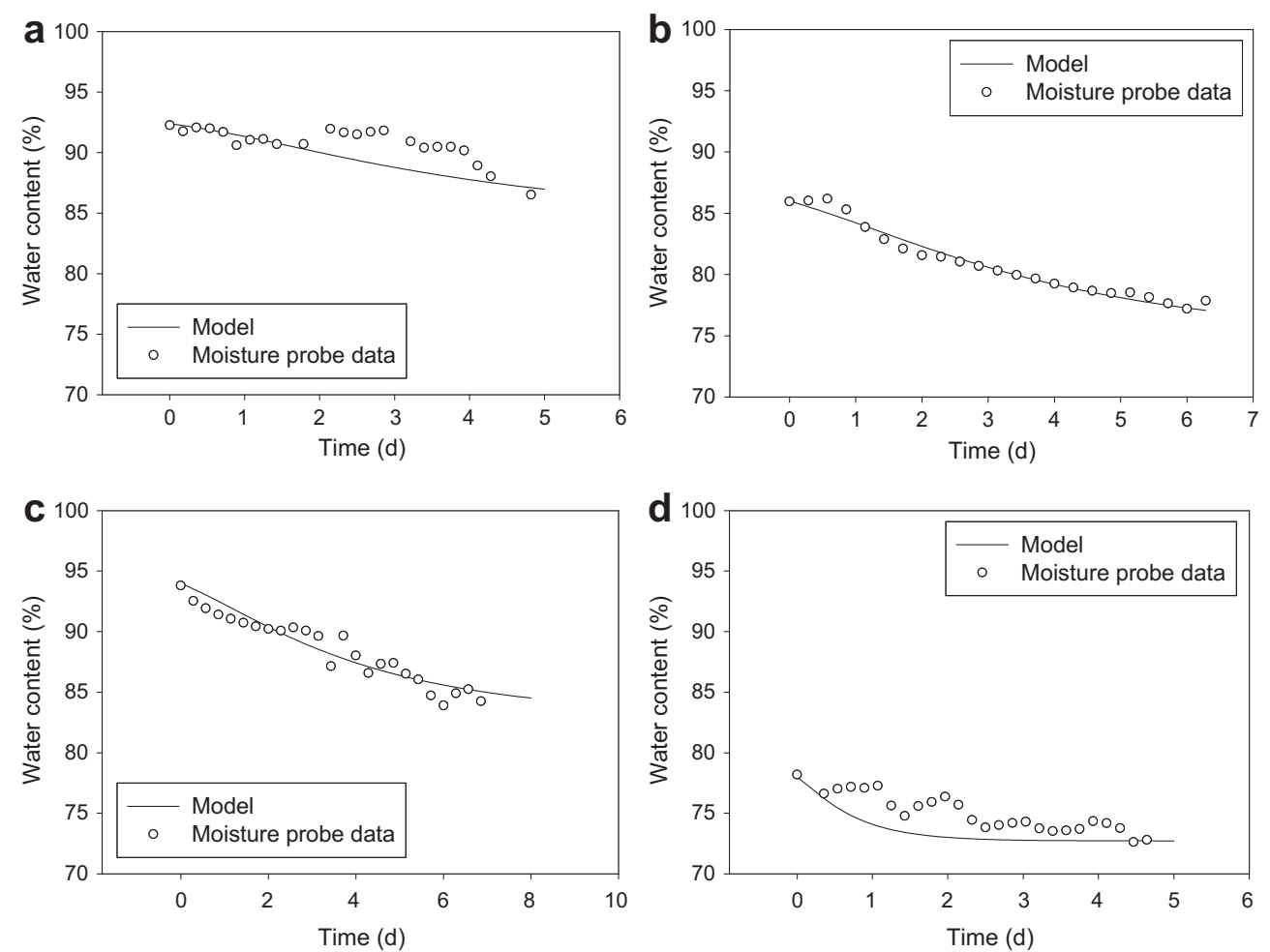

Fig. 2 - Model verifications corresponding to February (a), May (b) and (d) and June (c) with data from Sant Boi de Lluçanès (a, $b$ and c) and Alpens (d).

\subsection{Scenarios}

\subsubsection{Sludge dewatering}

The main goal of developing this model was to improve and standardise STW operation. In order to determine the most appropriate feeding frequency, different scenarios were tested by evaluating the influence of two variables: evapotranspiration and sludge layer height. Fig. 3 shows the curves of water loss corresponding to these scenarios. Dewatering curves represent moisture decrease during some days after sludge loading $(t=0)$, when moisture corresponds to the initial value ( $82 \%$ in this case). The sharp slopes of dewatering curves after sludge loading $(t=0)$ indicate that water is mainly lost during the first days of resting. The curves become then more flat until the asymptote, when moisture remains constant. In the model, the temporal distribution of water loss is mainly governed by the consolidation of the sludge layer caused by its pressure, thus the sludge layer height is the main parameter influencing the shape of the dewatering curves. This means that, after the same resting time water loss increases with the sludge layer thickness, during the first 2 years of operation the water loss (up to $25 \%$, Fig. 3a) is lower than during the following years (>30\%, Fig. $3 \mathrm{~b}$ and c).

As expected, evapotranspiration has a significant effect on the dewatering performance of STW. If we look at the scenario with a sludge layer of $20 \mathrm{~cm}$ (Fig. 3a), the water loss increases from 5 to $20 \%$ with ET of 2.5 and $14.65 \mathrm{~mm} / \mathrm{d}$, respectively. Indeed, the slope of the moisture curve and the sludge dryness achieved at the end of the resting period increases with ET. This is even more evident in a thick sludge layer, when the sludge dryness increases significantly (Fig. 3b and c).

\subsubsection{Feeding frequency}

The dewatering curves obtained from the scenarios investigated are useful to determine the optimum feeding frequency, which is the main practical application of this model. Indeed,

Table 2 - Results from the statistical analysis assessing the model performance in the 4 verifications performed: Mean Absolute Error (MAE), Mean Square Error Normalised (RMSEN), Pearson's Correlation Coefficient (PCC), Normalised Mean Bias Error (NMBE) and Nash-Sutcliffe Coefficient of Efficiency (CE).

\begin{tabular}{lcccc} 
Error criterion & Verification 1 & Verification 2 & Verification 3 & Verification 4 \\
\hline MAE & 1.12 & 0.34 & 0.75 & 1.23 \\
RMSEN & 0.01 & 0.01 & 0.01 & 0.01 \\
PCC & 0.73 & 0.99 & 0.95 & 0.79 \\
NMBE & -0.01 & 0.00 & 0.00 & 0.02 \\
CE & -0.05 & 0.97 & 0.60 & 0.39 \\
\hline
\end{tabular}



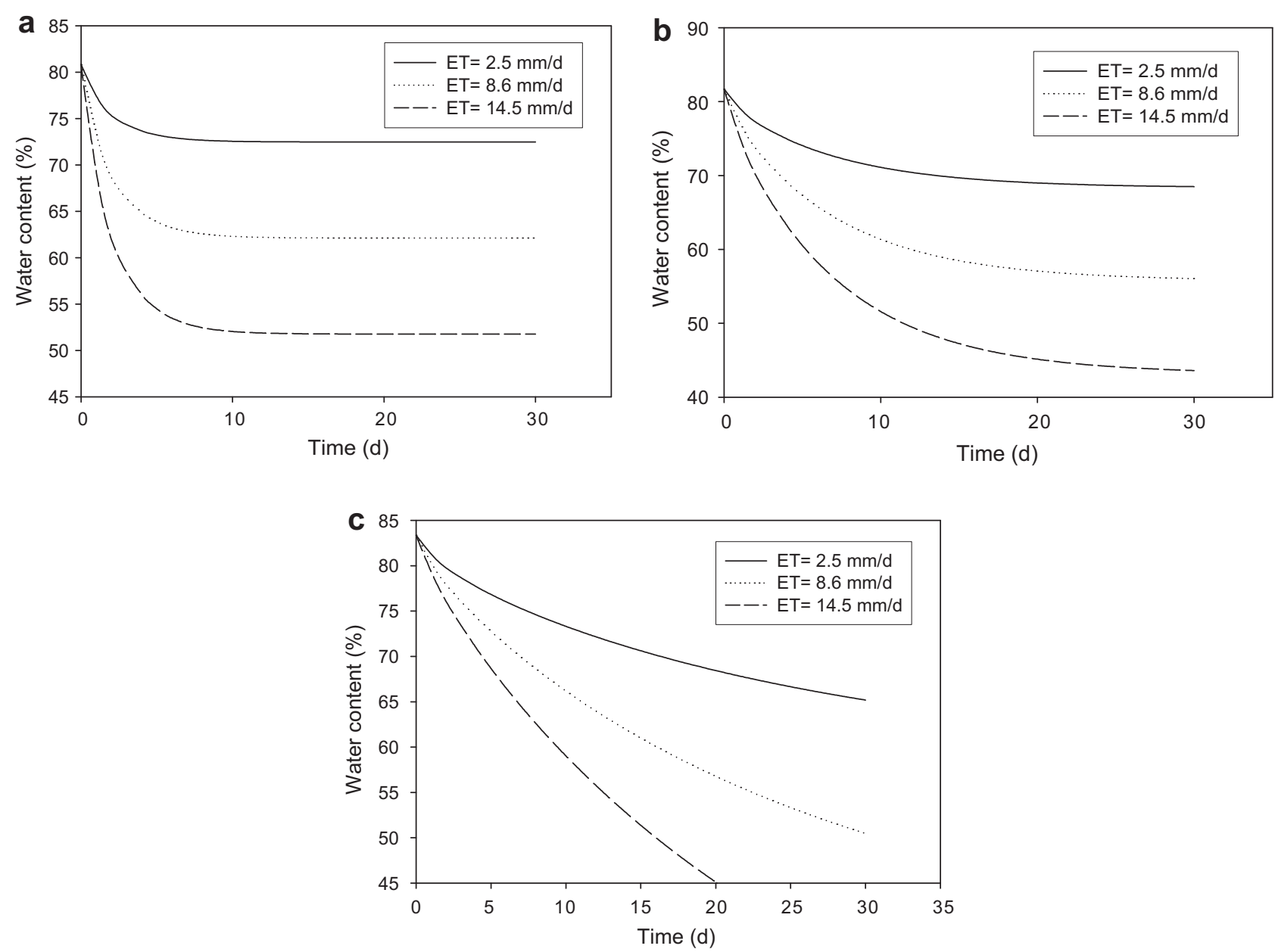

Fig. 3 - Scenarios corresponding to different climates within the Mediterranean Region: mountain (2.5 mm/d), coastal $(8.6 \mathrm{~mm} / \mathrm{d})$ and dry continental $(14.5 \mathrm{~mm} / \mathrm{d})$. The sludge height is $20 \mathrm{~cm}(\mathrm{a}), 40 \mathrm{~cm} \mathrm{(b)}$ and $80 \mathrm{~cm}(\mathrm{c})$.

all curves corresponding to the same sludge height reach the asymptote at the same time (10 and 20 days for sludge height of 20 and $40 \mathrm{~cm}$, respectively). This means that different ET influence only slightly the dewatering time. According to this, the sludge layer height influences the feeding frequency, while ET is responsible for the sludge dryness achieved during the resting period between feedings. As shown by the peak of the cumulative average of the derivative distribution (Fig. 4), a system with a sludge layer of 20,40 and $80 \mathrm{~cm}$, corresponding to 2, 4 and 8 years of operation, should be fed every $2.5,10$, and 30-40 days, respectively. This patter is confirmed by the curves simulated by the model (Fig. 3): with a sludge layer of $20 \mathrm{~cm}$ (Fig. 3a) the water content is reduced from 10 to $20 \%$ during the first 3 days after feeding; whereas with a sludge layer of $40 \mathrm{~cm}$ (Fig. 3b) 10 days are needed to reach the same water loss (10-20\%). Concerning the feeding procedure, single loading event is recommended to increase the sludge pressure and enhance sludge dewatering, according to the hypothesis of this model.

The optimum feeding frequency corresponding to each sludge height was extrapolated from the scenarios. 3 points were used to derive Eq. (14), and the optimum feeding frequency was determined as a function of the sludge height. This corresponds to the time interval of maximum water loss. If not enough time is left between feedings, the sludge dryness achieved between feedings is reduced increasing the sludge height, decreasing the duration of operation cycles and increasing the treatment costs.

$\mathrm{T}(d)=62.5 \cdot \mathrm{H}^{2}(\mathrm{~m})$

\subsubsection{Sludge loading rate}

The maximum water loss corresponding to each feeding frequency was calculated from the derivate of the dewatering curve (Table 3).

SLR, determined by means of the least squares regression of Eq. (13), results as a function of ET, time between feedings ( $\mathrm{T}$ ) and sludge height (H) (Eq. (15)). Note that $R^{2}>0.98$ in all the correlations tested.

$$
\begin{aligned}
\mathrm{SLR}= & \mathrm{T} \cdot[(0,596 \cdot \mathrm{ET}+3,863) \cdot \ln (\mathrm{H})+(-0,014 \cdot \mathrm{T}+1,239) \cdot \mathrm{ET} \\
& +(-0.014 \cdot \mathrm{T}+7.638)]
\end{aligned}
$$

where SLR is the height of sludge loading $(\mathrm{mm}), \mathrm{H}$ is the sludge layer height $(\mathrm{m}), \mathrm{T}$ is the time between feedings $(\mathrm{d})$ and ET is the evapotranspiration $(\mathrm{mm} / \mathrm{d})$. In this way the model can be used to determine operational criteria and improve STW operation. According to Nielsen (2005), the main STW operational problems are 1) overloading, 2) insufficient duration of resting periods and 3) inadequate operation criteria. Systems 

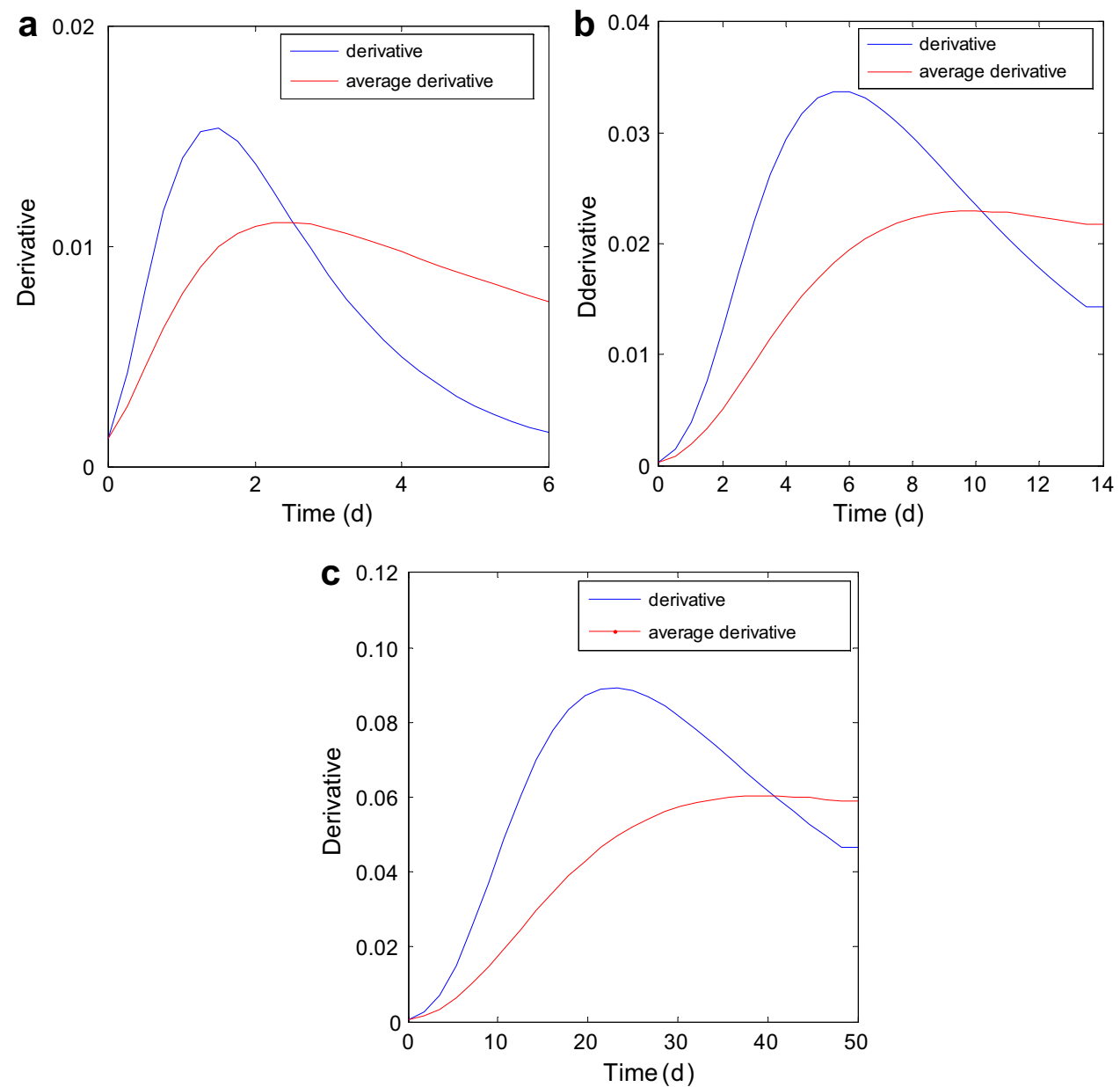

Fig. 4 - Intersection between the derivative of the dewatering curve and the mean of the derivative curve in each time step, the sludge height is $20 \mathrm{~cm}(\mathrm{a}), 40 \mathrm{~cm}$ (b) and $80 \mathrm{~cm}$ (c).

with short resting periods show slow dewatering and permanent water content on the sludge surface, leading to a rapid growth of the sludge layer and anaerobic conditions with consequent odours emission. In this way, the standardisation of parameters such as the feeding frequency and loading rate can be helpful to improve the performance of STW resulting in a drier final product and reducing STW operation costs.

\subsection{Model reliability and further implementations}

In this model, the sludge layer height increase caused by sludge feeding was not considered, thus the results are independent from the sludge volume fed. This assumption is acceptable considering that the sludge fed is rapidly drained and the increase of sludge layer height after each feeding is insignificant with respect to the total sludge thickness. However, the introduction of the sludge volume fed as model input would improve further the model performance.

The model was validated with data from systems fed with secondary sludge from extended aeration, thus the sludge quality was not introduced as a variable of the model. However, the sludge dewaterability might change according to sludge properties. The introduction of this parameter could improve the model performance and enlarge its range of application.

Sludge permeability along the vertical sludge profile was considered constant, while after some days of resting the surface layers tend to be dryer and less permeable than the bottom. By considering the decrease in sludge permeability over the resting time, sludge drainage would be delayed during the first instants after loading, but the feeding frequency would probably not be affected.

The model was calibrated by determining the consolidation and oedometric coefficients from data collected by probes located within the top layer of the sludge. Recorded values were assumed to be constant along the vertical sludge profile. However, the introduction of different sludge layers and the calibration with moisture probes at different depths would make the model more reliable. In the scenarios and in the determination of the time frequency, the consolidation and oedometric coefficients were considered constant over time. This assumption should be tested with experimental data from sludge with different age.

This model can be used to estimate water loss during some days or weeks of resting between feedings. However, the model hypothesis should be reformulated for dry sludge, which can be found after months or years without fresh 
Table 3 - Sludge dewatering $(\mathrm{mm} / \mathrm{d})$ as function of sludge height $(H)$ and evapotranspiration (ET) calculated from the derivate of the dewatering curve shown in Fig. 4.

\begin{tabular}{lcccc} 
Feeding & & \multicolumn{3}{c}{ ET $(\mathrm{mm} / \mathrm{d})$} \\
\cline { 3 - 5 } frequency $(\mathrm{d})$ & $H(\mathrm{~m})$ & 2.5 & 8.6 & 14.5 \\
\hline 3.5 & & 4.28 & 7.69 & 10.98 \\
& 0.25 & 9.31 & 13.27 \\
& 0.30 & 5.27 & 10.71 & 15.12 \\
7 & 0.35 & 6.16 & & \\
& & & & \\
& 0.35 & 4.23 & 7.60 & 10.86 \\
& 0.40 & 4.95 & 8.81 & 12.54 \\
14 & 0.50 & 6.20 & 10.79 & 15.24 \\
& & & & \\
& 0.50 & 4.28 & 7.69 & 10.98 \\
& 0.55 & 4.80 & 8.55 & 12.19 \\
28 & 0.60 & 5.27 & 9.34 & 13.27 \\
& & & & \\
& 0.70 & 4.23 & 7.60 & 10.86 \\
& 0.80 & 4.95 & 8.81 & 12.54 \\
& 0.90 & 5.60 & 9.86 & 13.99 \\
\hline
\end{tabular}

sludge loading. In fact, the hypothesis of this model are only valid for saturated conditions and sludge dryness implying a consolidation degree higher than the consolidation settlement after infinite time $\left(S_{\infty}\right)$ would invalidate the model. During the last decades, efforts have been done in order to understand consolidation in unsaturated soils (Conte, 2004). This could be useful in order to improve the model and enlarge its range of application.

Model performance could also be improved by introducing the effect of plants. It is well known that plants contribute to sludge dewatering by evapotranspiration, but also by cracking the sludge surface with the movement of stems. Such phenomena may contribute positively to sludge dewatering by accelerating water percolation. This aspect was partially and indirectly considered in the model by means of the $C_{v}$ term, which influences the consolidation time. However, the introduction of sludge cracking in the model is limited by the difficulty of determining stems distribution within the sludge. Regarding evapotranspiration, the standardised reference crop evapotranspiration was assumed in this study. In this sense, the introduction of the actual evapotranspiration of different seasons and climate conditions would improve the model reliability. Thus, ET calibration with real data is suggested prior to the model application.

Due to its relevance in the water balance in constructed wetlands, precipitation was introduced into the model. However, the model response to precipitation was not tested here, since no rainfalls occurred during the periods considered. Consequently, rainfalls were not considered in the scenarios studied.

Even though the model is focused on sludge dewatering, mineralisation is another key process in STW. By introducing a mineralisation term, the model would consist of a powerful tool to optimise STW operation, since it would include the main process of sludge treatment in constructed wetlands (dewatering and mineralisation). However, this requires a deep knowledge on the mineralisation process in STW, which is nowadays still not available.

\section{Conclusions}

A dewatering model capable of simulating sludge dewatering in STW was developed and solved by means of a finite difference method. The model combined Terzaghi's consolidation theory, representing water loss by percolation and ET. It was validated with moisture data from one pilot plant and two full-scale STW.

According to the verification test, the model is able to predict water loss with time, differing from real moisture values by less than $1 \%$. Different scenarios were considered to determine the optimal feeding frequency, which depends on the sludge layer height, hence on the years of operation. In this way, systems with a sludge layer of $20 \mathrm{~cm}, 40 \mathrm{~cm}$ and $80 \mathrm{~cm}$ (corresponding to 2, 4 and 8 years of operation), should be fed every 2.5, 10 and 30-40 days, respectively. On the other hand, evapotranspiration (ET) has no effect on the feeding frequency.

According to the model output, the sludge loading rate is determined as a function of evapotranspiration, feeding frequency and sludge height.

\section{Acknowledgements}

This work was funded by the Spanish Ministry of Environment (MMARM, Projects A335/2007 and 087/PC08). E. Uggetti kindly acknowledges the Universitat Politècnica de Catalunya for her PhD grant.

\section{R E F E R E N C E S}

Akratos, C.S., Papaspyros, J.N.E., Tsihrintzis, V.A., 2009. Artificial neural network use in ortho-phosphate and total phosphorus removal prediction in horizontal subsurface flow constructed wetlands. Biosystems Engineering 102 (2), 190-201.

Allen, R.G., Pereira, L.S., Howell, T.A., Jensen, M.E., 2011. Evapotranspiration information reporting: I. Factors governing measurement accuracy. Agricultural Water Management 98, 899-920.

ASCE-EWRI, 2005. The ASCE Standardized Reference Evapotranspiration Equation Technical Committee Report Of the Environmental and Water Resource Institute of the American Society of Civil Engineers from the Task Committee on Standardization of Reference Evapotranspiration.

Baird, K.J., Maddock, T., 2005. Simulating riparian evapotranspiration: a new methodology and application for groundwater models. Joutnal of Hidrology 312 (1-4), 176-190.

Bianchi, V., Peruzzi, E., Masciandaro, G., Ceccanti, B., Ravelo, S., Iannelli, R., 2010. Efficiency assessment of a reed bed pilot plant (Phramites australis) for sludge stabilisation in Tuscany (Italy). Ecological Engineering. doi:10.1016/ j.ecoleng.2010.05.008.

Borin, M., Milani, M., Salvato, M., Toscano, A., 2011. Evaluation of phragmites australis (Cav,) evapotranspiration in Northern and Southern Italy. Ecological Engineering 37, 721-728.

Chang, I.L., Lee, D.J., 1998. Ternary expression stage in biological sludge dewatering. Water Research 32 (3), 905-914.

Chu, C.P., Lee, D.J., 1999. Three stage of consolidation dewatering of sludges. Journal of Environmental Engineering 125 (10), 959-965. 
Conte, E., 2004. Consolidation analysis of unsaturated soils. Canadian Geotechnical Journal 41 (4), 599-612.

Giraldi, D., Iannelli, R., 2009. Short-term water content analysis for the optimization of sludge dewatering in dedicated constructed wetlands (red bed systems). Desalination 246, 92-99.

Lambe, W., Withman, R.V., 1979. Soil Mechanics. SI Version. John Wiley \& Sons, New York, NY, 553 pp.

Lienard, A., Duchene, P., Gorini, D., 1994. A study of activated sludge dewatering in experimental reed-planted or unplanted sludge drying beds. Water Science and Technology 32, 251-261.

Magri, M.E., Suntti, C., Voltolini, C.A., Philippi, L.S., 2010. Performance of different macrophytes species in constructed wetlands systems for anaerobic sludge dewatering, experience from Southern Brazil. In: Proceeding of Conference: 12th International Conference on Wetland Systems for Water Pollution Control 4-8 October. Venice (Italy).

Melidis, P., Gikas, G.D., Akratos, C.S., Tsihrintzis, V.A., 2010. Dewatering of primary settled urban sludge in a vertical flow wetland. Desalination 250 (1), 395-398.

Nielsen, S., 2003. Sludge treatment in wetland systems. In: Dias, V., Vymazal, J. (Eds.), Proceedings of Conference: The Use of Aquatic Macrophytes for Wastewater Treatment in Constructed Wetlands (IWA) 8-10 May, Lisbon (Portugal).

Nielsen, S., 2005. Mineralization of hazardous organic compounds in a sludge reed bed and sludge storage. Water Science and Technology 51 (9), 109-117.

Nielsen, S., 2007. Helsinge sludge reed beds systems: reduction of pathogenic microorganisms. Water Science \& Technology 56 (3), 175-182.

Obarska-Pempkowiak, H., Tuszynska, A., Sobocinski, Z., 2003. Polish experience with sewage sludge dewatering in reed systems. Water Science \& Technology 48 (5), 111-117.

Stefanakis, A.I., Akratos, C.S., Melidis, P., Tsihrintzis, V.A., 2009. Surplus activated sludge dewatering in pilot-plant sludge drying reed beds. Journal of Hazardous Materials 172, 1122-1130.
Stefanakis, A.I., Tsihrintzis, V.A., 2011. Dewatering mechanisms in pilot-scale sludge drying reed beds: effect of design and operational parameters. Chemical Engineering Journal 172, 430-443.

Summerfelt, S.T., Adler, P.R., Glenn, D.M., Kretschmann, R.N., 1999. Aquaculture sludge removal and stabilization within created wetlands. Aquacultural Engineering 19, 81-92.

Terzaghi, K., Peck, R.B., 1967. Soil Mechanics in Engineering Practice, second ed. Wiley, New York.

Troesch, S., Liènard, A., Molle, P., Merlin, G., Esser, D., 2008. Sludge drying reed beds: a full and pilot-scales study for activated sludge treatment. In: Proceeding of Conference 11th Int. Conf. Wetland Syst. for Water Pollut. Control. 1-7 November. Indore (India).

Uggetti, E., Llorens, E., Pedescoll, A., Ferrer, I., Castellnou, R., García, J., 2009. Sludge dewatering and stabilisation in drying reed beds: characterisation of three full-scale systems in Catalonia, Spain. Bioresource Technology 100 (17), 3882-3890.

Uggetti, E., Ferrer, I., Llorens, E., García, J., 2010. Sludge treated wetlands: a review on the state of the art. Bioresource Technology 101 (9), 2905-2912.

Uggetti, E., Ferrer, I., Molist, J., García, J., 2011. Technical, economic and environmental assessment of sludge treatment wetlands. Water Research 45 (2), 573-582.

Vincent, J., Molle, P., Wisniewski, C., Lienard, A., 2011. Sludge drying reed beds for septage treatment: towards design and operation recommendations. Bioresource Technology 102 (17), 8327-8330.

Zhou, L., Zhou, G., 2009. Measurement and modeling of evapotranspiration over a reed (Phragmites australis) marsh in Northeast China. Journal of Hydrology 372, 41-47.

Zhongpong, S., Bin, W., Wei, S., Wenming, S., Changzuo, W., Daian, Y., Zheng, L., 2010. Evapotranspiration estimation based on the SEBAL model in the Nansi Lake wetland of China. Mathematical and Computer Modelling. doi:10.1016/ j.mcm.2010.11.039. 